\title{
A Comprehensive Study Supporting Beneficial Uses of Produced Water in Southeastern New Mexico
}

Robert Sabie, Jr. ${ }^{1}$, Dr. Jeri Sullivan Graham ${ }^{2,3}$, Dr. KC Carroll ${ }^{4}$, Martha Cather ${ }^{5}$, Dr. Binod Chaudhary ${ }^{4}$, Wayne Cox ${ }^{4}$, Dongyi Chen ${ }^{5}$, Dr. Robert Flynn ${ }^{4}$, Cristobal Gallegos ${ }^{5}$, Woods Houghton ${ }^{4}$, Guanyu $\mathrm{Ma}^{4}$, Kwabena Sarpong ${ }^{4}$, Zachary Stoll ${ }^{4}$, Aracely Tellez ${ }^{4}$, Spencer Willman ${ }^{4}$, Dr. Pei Xu${ }^{4}$, Dr. Alexander Fernald ${ }^{1},{ }^{4}$

${ }^{1}$ New Mexico Water Resources Research Institute | ${ }^{2}$ Los Alamos National Laboratory | ${ }^{3} \mathrm{New}$ Mexico Energy, Minerals, and Natural Resource Department | ${ }^{4} \mathrm{New}$ Mexico State University | ${ }^{5} \mathrm{New}$ Mexico Institute of Mining and Technology
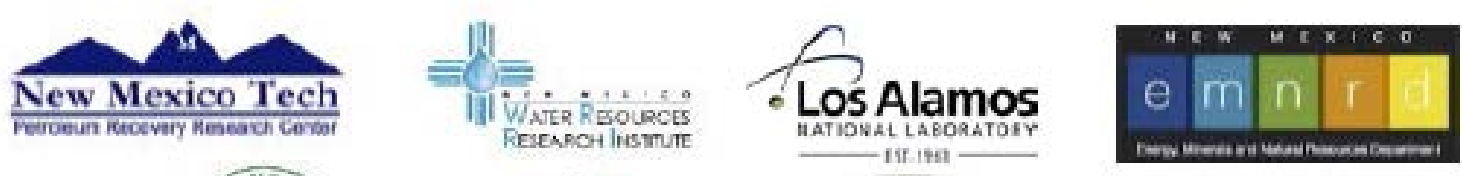

Jeri Sullivan Graham

Geological Society of America September 26, 2016 Denver, Colorado
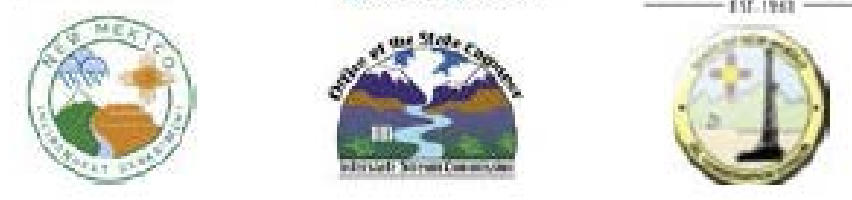


\section{The Driving Issues....}

- Water is more scarce and demands for fresh water are increasing in Eddy and Lea Counties of southeastern New Mexico;

- Oil and gas industries devote considerable financial resources to managing large volume produced water; and,

- Decision-makers and stakeholders require information regarding produced water spatial distribution, quality and volume, geochemical composition, the regulatory framework, available treatment options, and water quality thresholds for different potential uses.

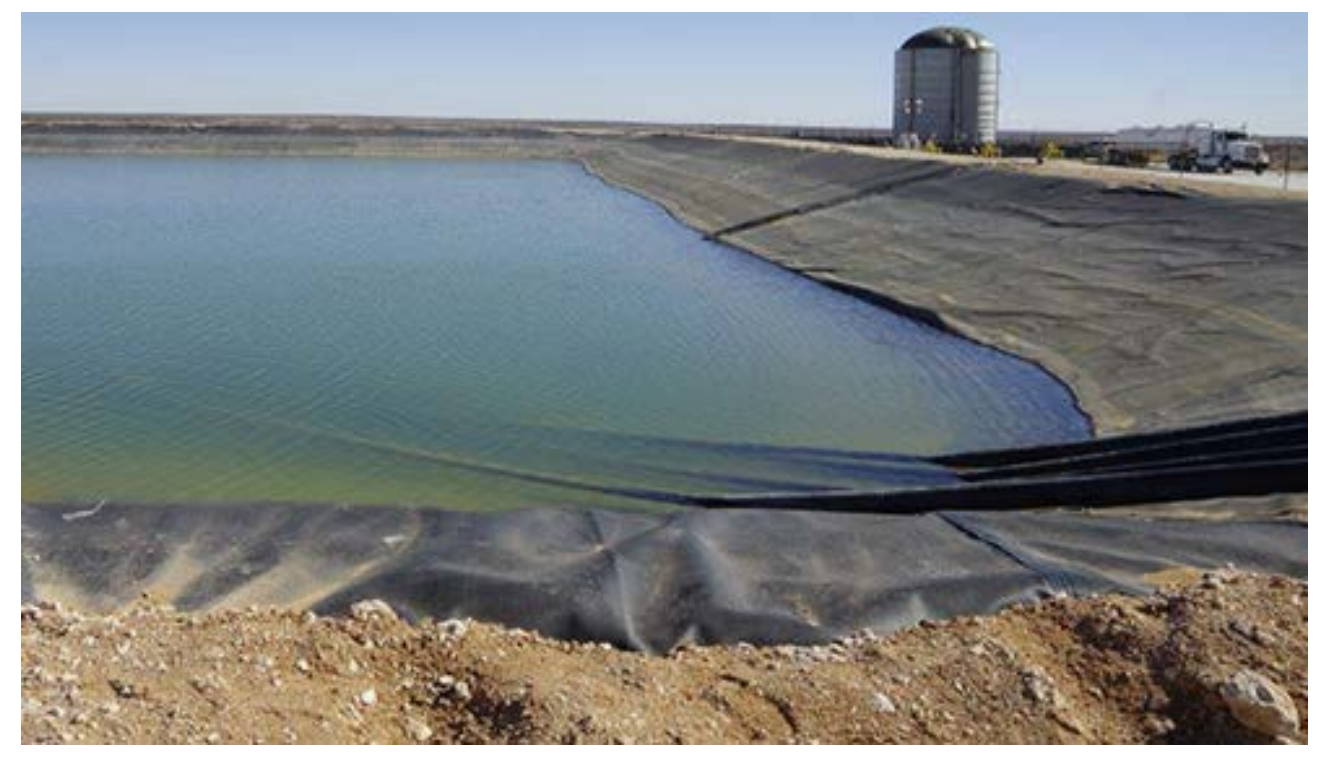




\section{Persistent Drought}

- Persistent drought conditions have reduced fresh water availability

- Increased oil and gas production requires costly management of produced water

- Treated produced water may be an alternative source for oil and gas, agriculture, mining, and stream augmentation

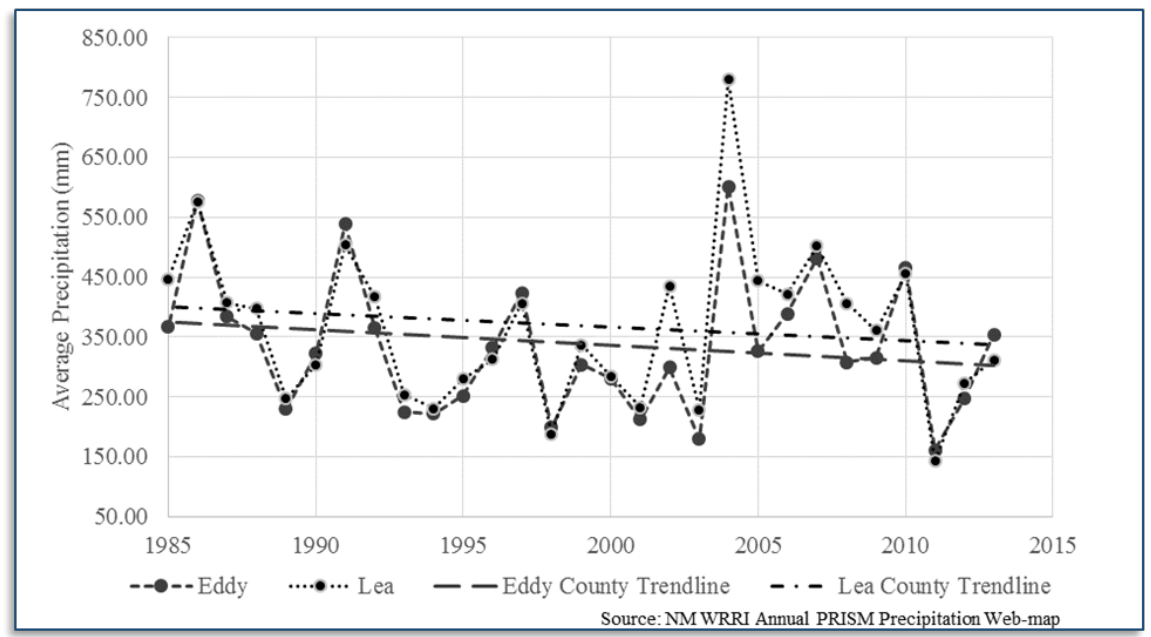

Average Annual Rainfall
Percent of Eddy and Lea Counties in Drought Conditions

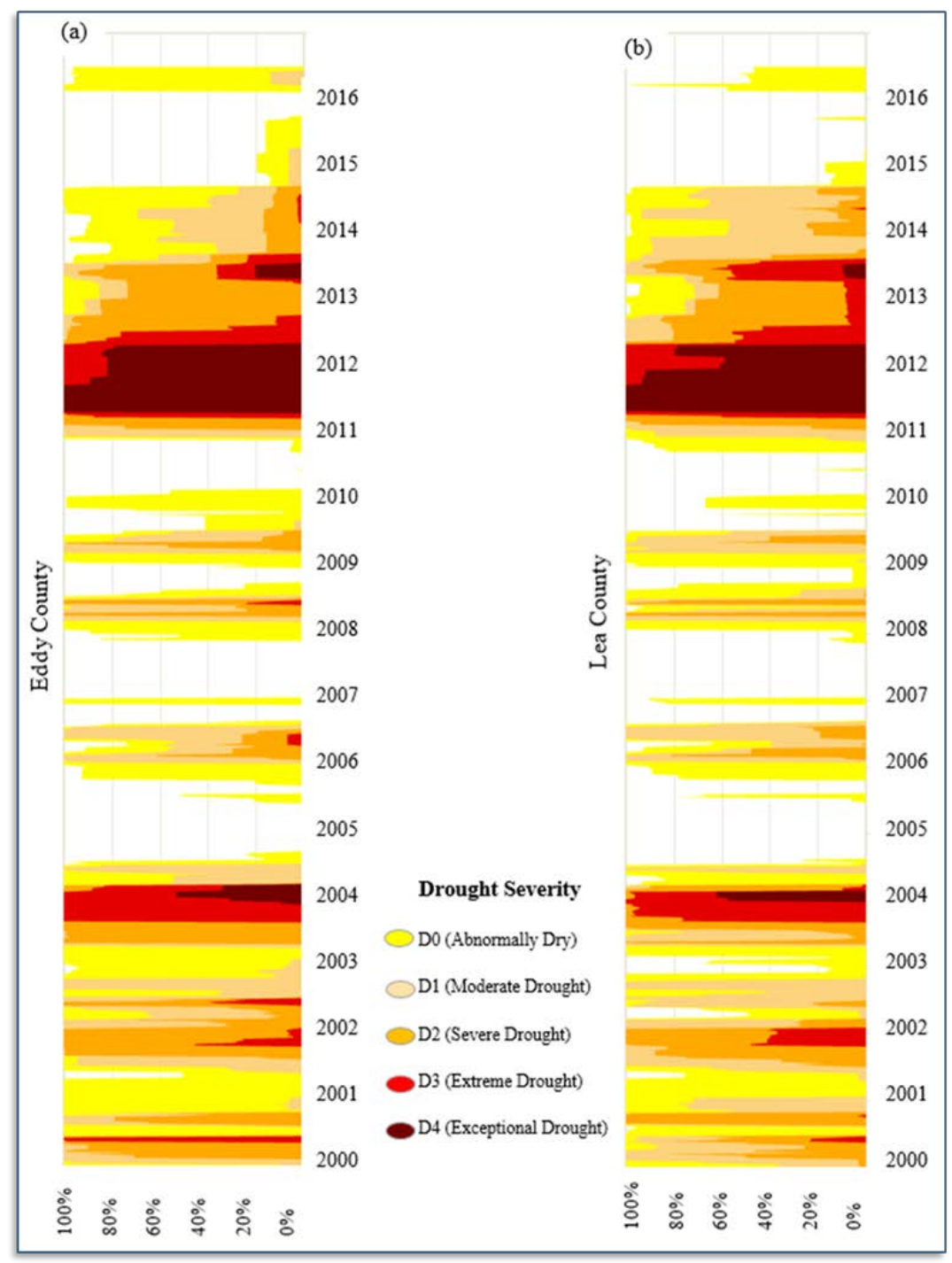




\section{Oil and Gas Production in Lea and Eddy Counties Oil production (top) Gas Production (bottom)}

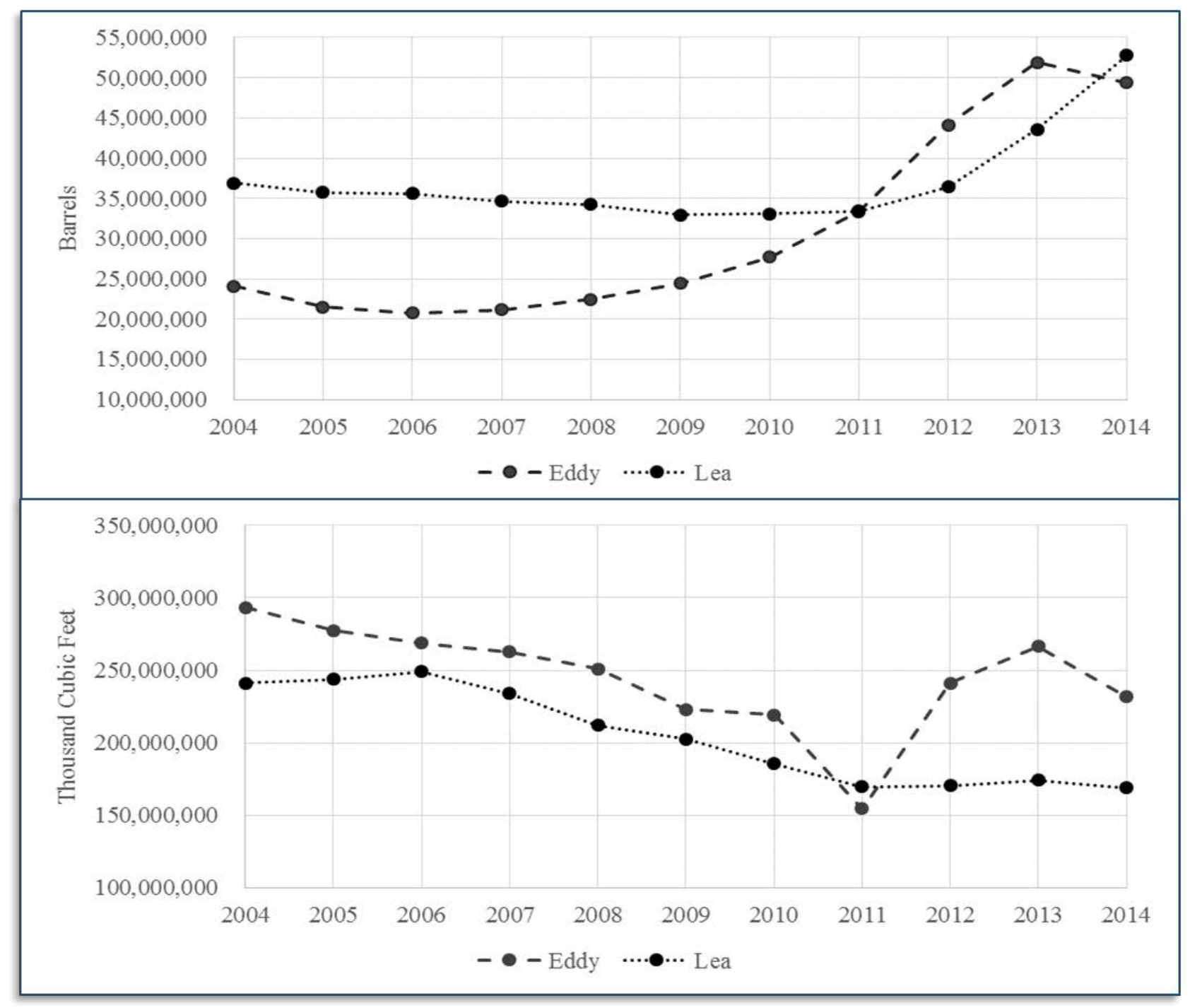




\section{GIS Methods}

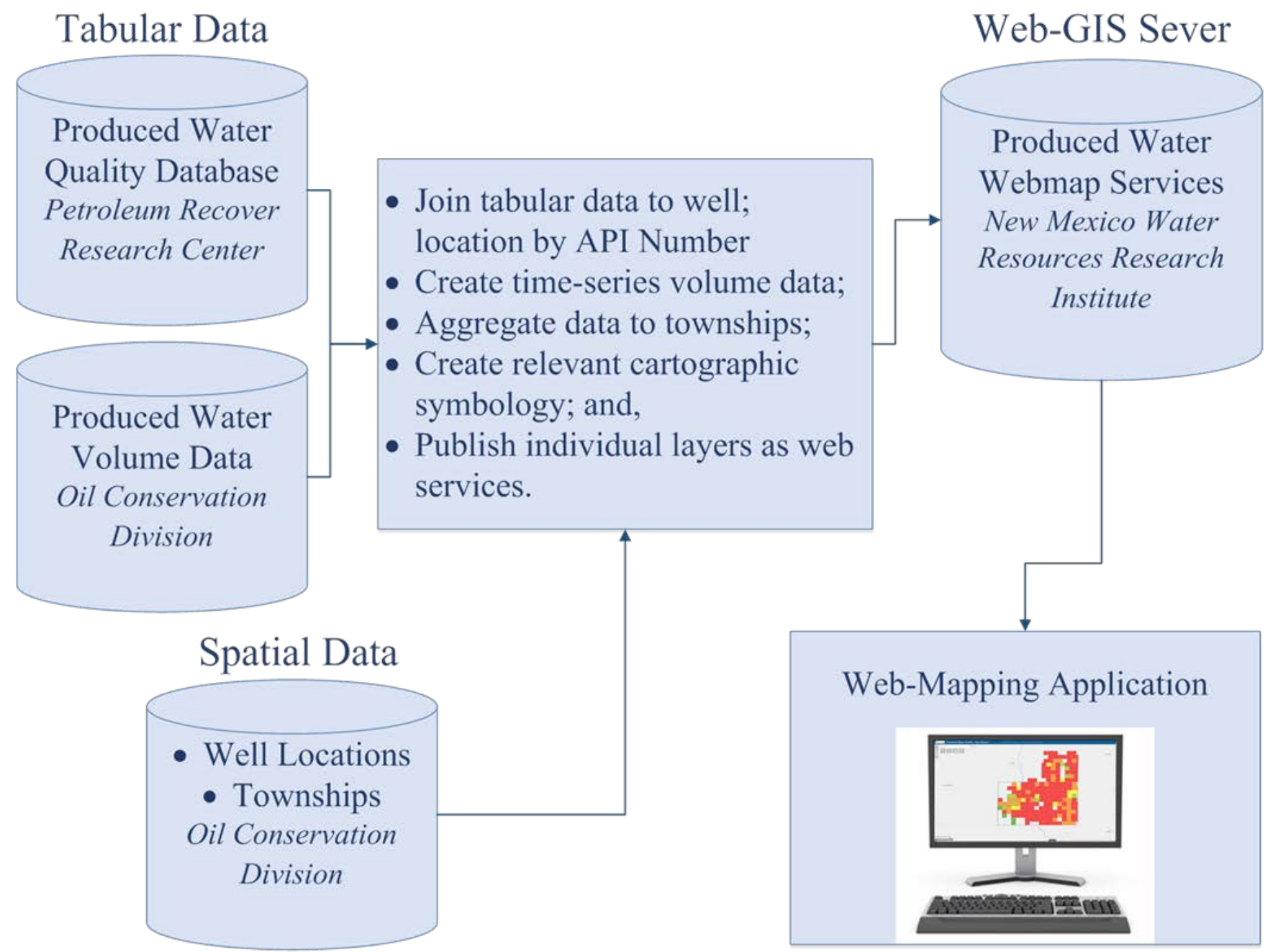




\section{GIS Results}

Total Produced Water Volume by Township

in Lea and Eddy Counties 2015

- Instructional video demonstrates the basic functions of the web-map applications

- $\quad$ Volume data for 29,864 wells in Eddy and Lea Counties

- $\quad$ Reported produced water volume exceeds 5,000 acre-feet in several townships

- Numerous functions available: search for wells by American Petroleum Institute (API) number

- Pop-up boxes include produced water volume attribute information and links to related OCD documents

- Download data as a .csv file

- Summarize produced water volume in a user defined area for years between 2004 to 2015.

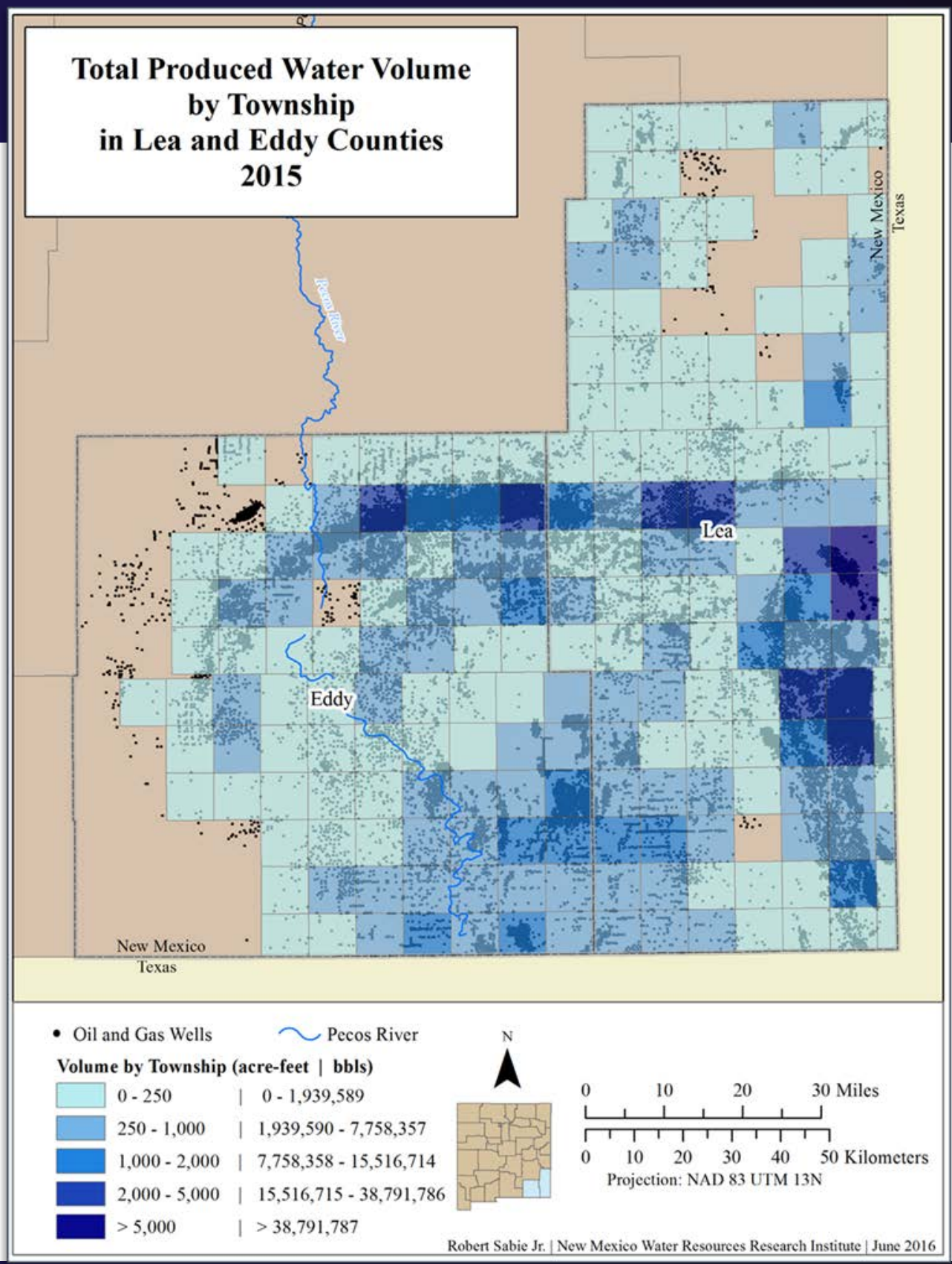




\section{Produced Water Quality Web-Map Interface}

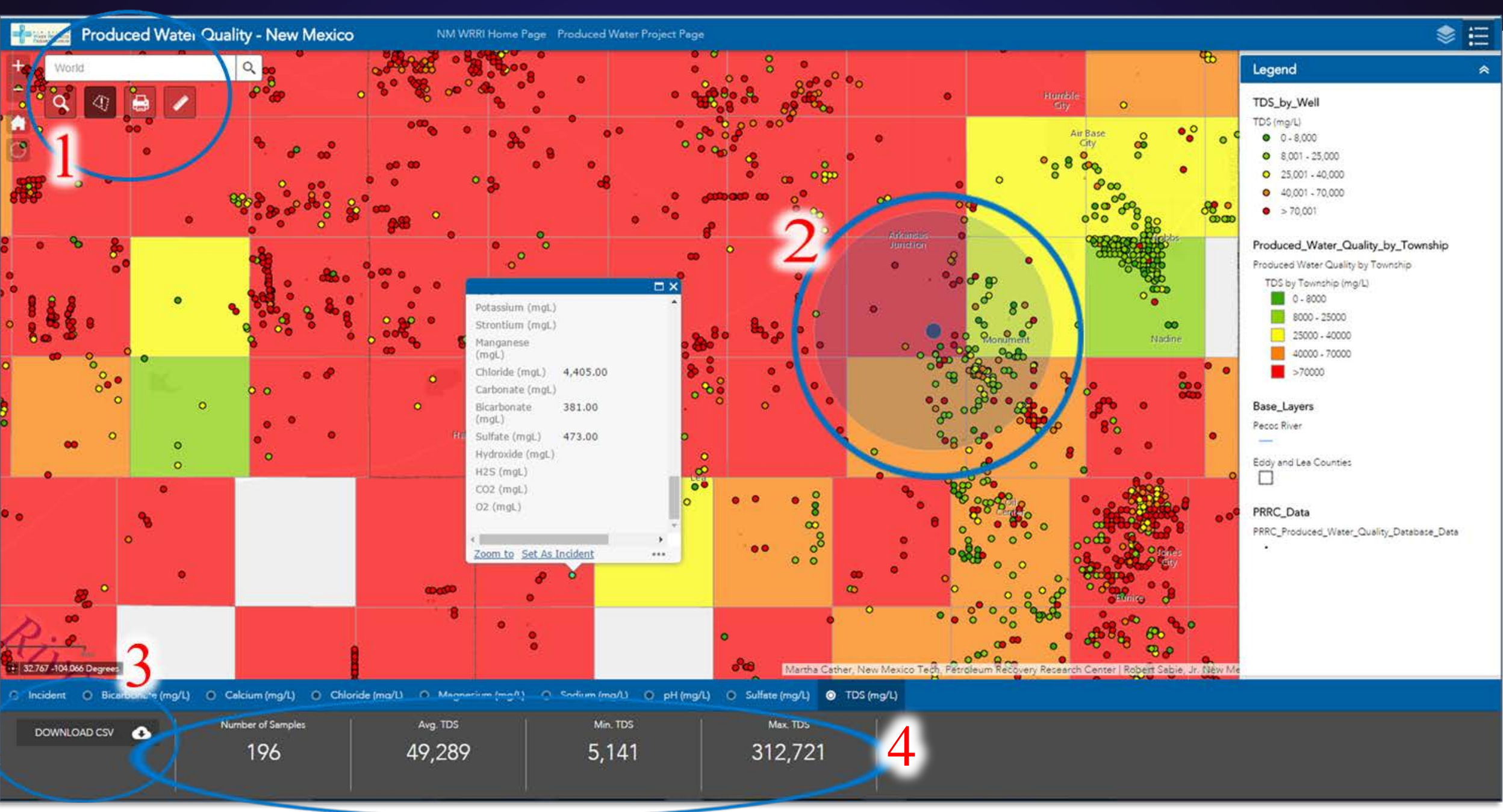

(1) Summary statistics tool for user defined area

(2) Defined Area

(3) Download selected data as .csv.

(4) number of samples, average, minimum, and maximum for eight water quality parameters 


\section{Treatment Decision Support Tool Decision Tree}

\section{Produced Water}

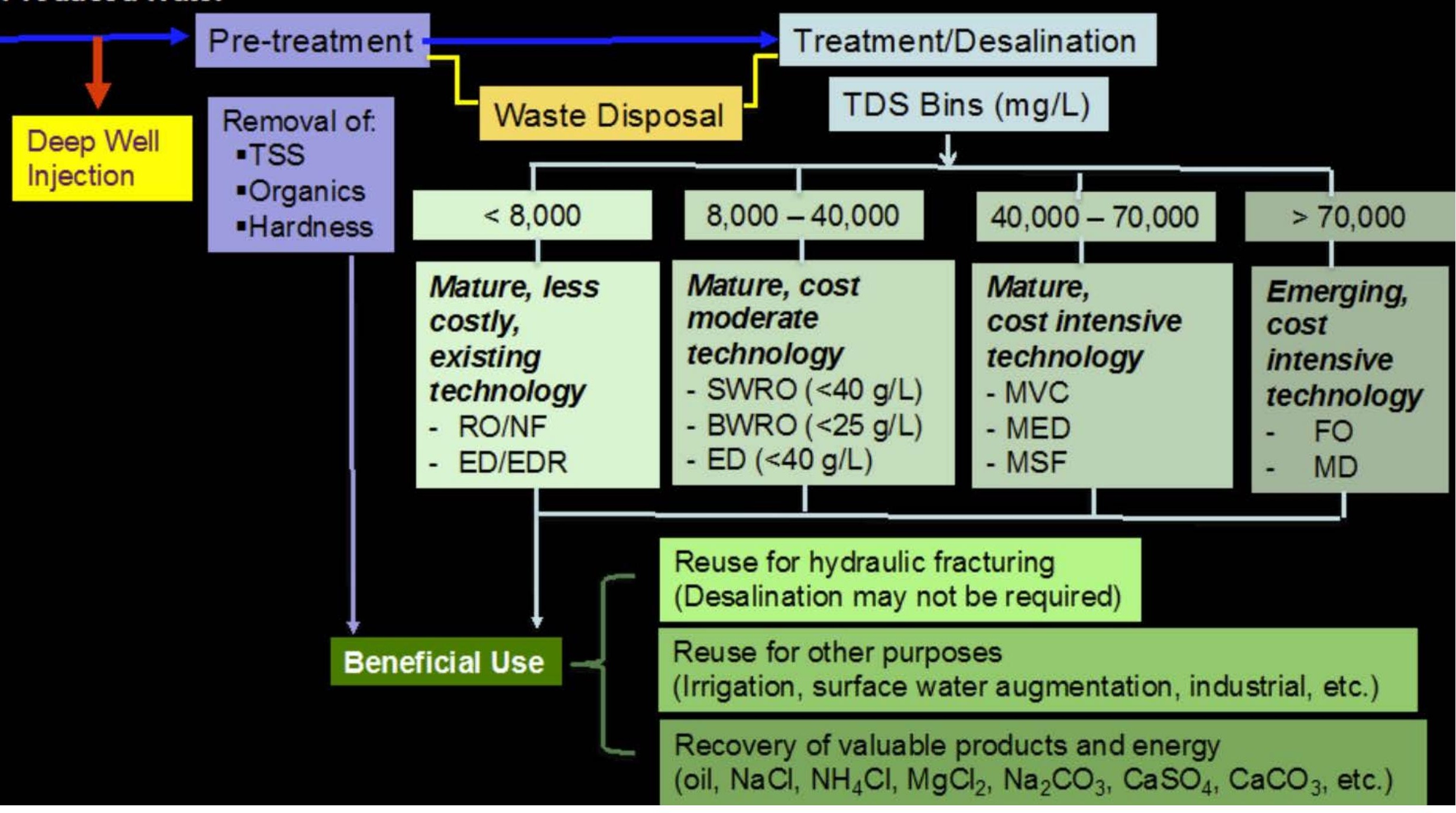




\section{Treatment and Reuse Input Page}

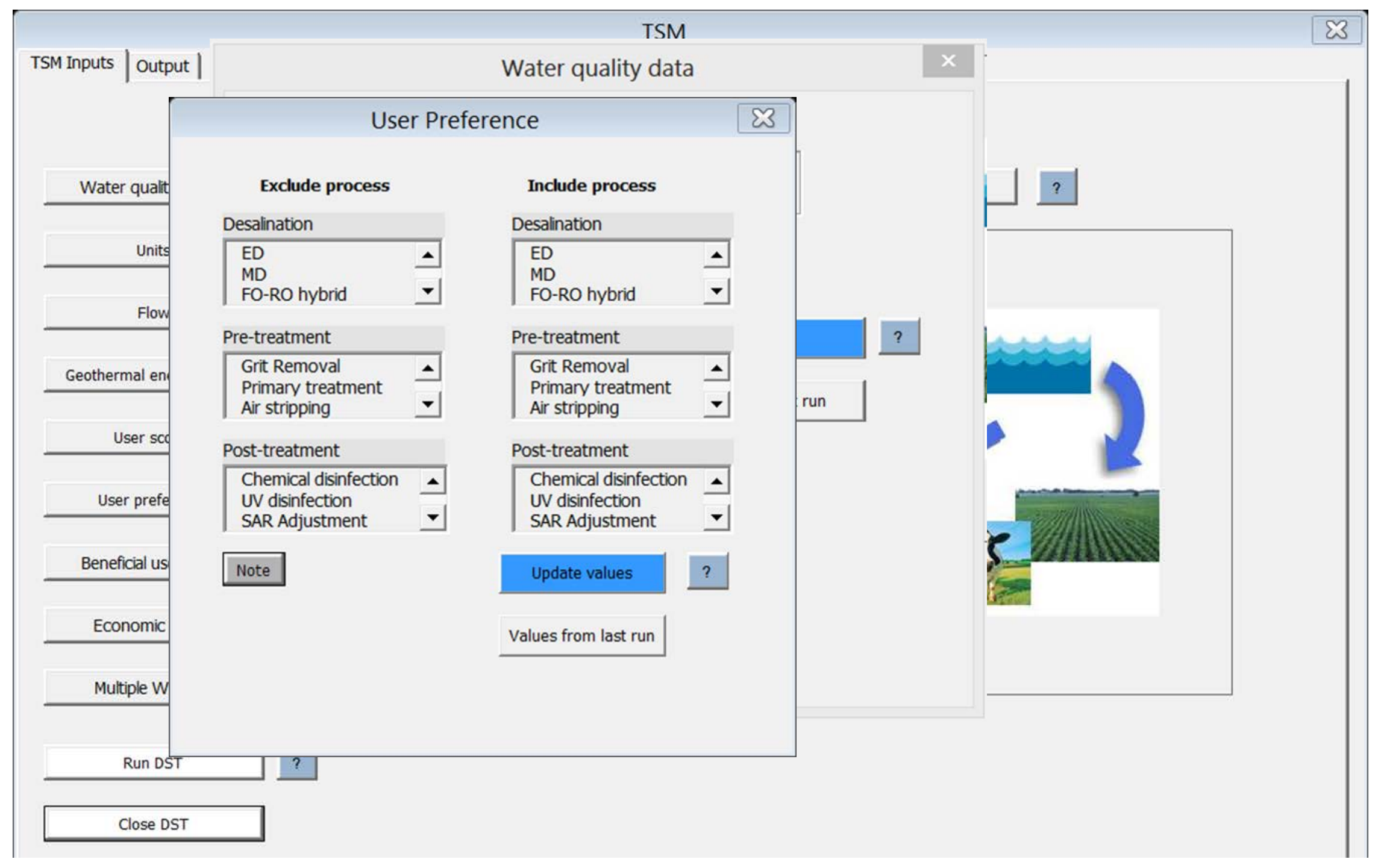




\section{User interaction - Output viewing options}

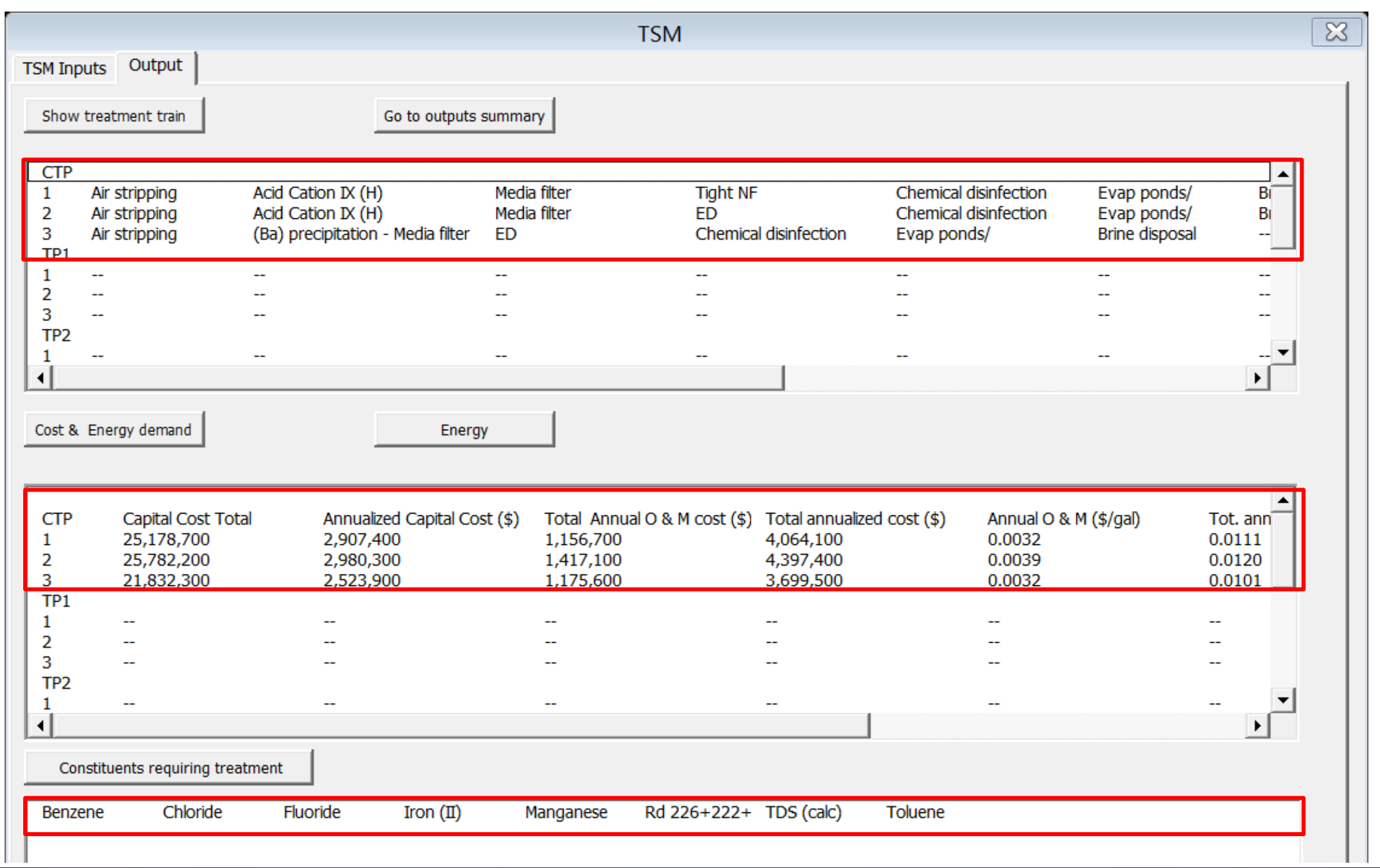




\section{Produced Water Regulatory Framework for Reuse}

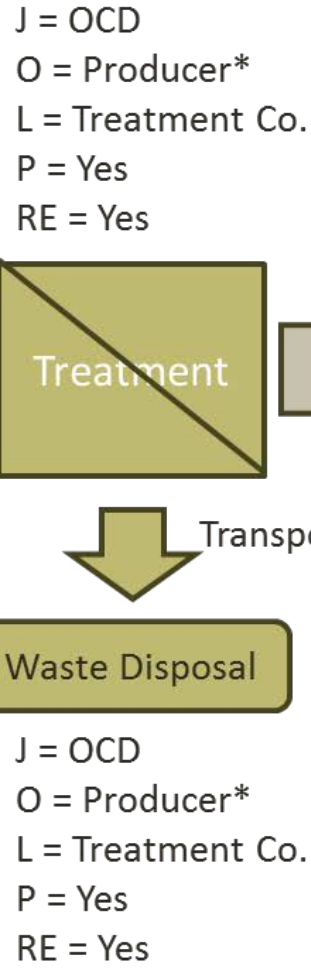

Key:

Jurisdiction $=\mathrm{J}$

Ownership $=0$

Legal Liability $=\mathrm{L}$

Permit $=\mathrm{P}$

Reporting $=\mathrm{RE}$

Permit+Right $=$ PR (OSE only)

* Unless sold/transferred by contract
- Hypothetical Case for Reuse outside of Oil and Gas Industry

- Partial or no consumption of clean water product

- Intentional discharge to Waters of the State/Navigable Waters (agriculture or surface water makeup) 


\section{Case Studies Utilizing PW}

- New Mexico: Farmington Pilot Treatment Study

- Rangeland Grass Rehabilitation

- BLM and NMED Jurisdiction

- Coalbed Methane PW, 10,000 mg/L TDS

- Multiple treatment stages-zeolite, NF, RO

- Multiple applications to rangeland

- Wyoming Pinedale Anticline

- CBM water for livestock forage production

- Chemical addition to manage SAR

- Bench-scale, Large-scale (100 acres) and Full-scale (800 acres)

- Wyoming DEQ jurisdiction

- Effluent requirements better than or equal to ambient class 2 receiving river

- Wellington, Colorado

- Municipal use

- MF/DAF/GAC + blending in a shallow GW well

- State Engineer and Colorado Energy Office Jurisdiction

- "Nontributary" designation. Ownership still in question? 


\section{Results-GIS Analysis}

- These web-map applications were developed with stakeholder and decisionmaker input and make critical information on produced water easily accessible;

- $\quad$ Areas with high reported volumes and low average TDS should be the starting point for further investigation of beneficial reuse of produced water;

- Several townships had wells with high reported volumes of produced water, however, it is possible these numbers are inflated because of reinjected produced water being used for water flooding and enhanced oil recovery, thus potentially cycled through the wells;

- $\quad$ Future work will need to address how is produced used for water flooding and enhanced oil recovery are reported to OCD in order to obtain more accurate measures of available produced water;

- $\quad$ Although these maps show general trends in produced water quality in Southeast New Mexico, additional water quality data are needed for each individual potential use case;

- Integration of geospatial data into a decision-support tool framework would be a logical next step for using this information to optimize potential beneficial use of produced water. 


\section{Results-Treatment}

- The i-DST selects appropriate treatment trains from 62 stored pretreatment, treatment, and post-treatment technologies for beneficial use of produced water based on produced water quality, reuse requirements, and user preference.

- Average TDS concentration of produced water in Eddy and Lea Counties is $\sim 90,000 \mathrm{mg} / \mathrm{L}$.

- Use of produced water for hydraulic fracturing and mining is economically feasible, while agricultural irrigation and instream augmentation of Pecos River is too expensive.

- Desalination methods for water $<40,000 \mathrm{mg} / \mathrm{L}$ include seawater RO or electrodialysis. Thermal treatment is needed for higher salinity waters.

- As no desalination process is required, reusing for cross-link gel system hydraulic fracturing has a relatively low cost at $\$ 5 / \mathrm{kgal}$ $(\$ 0.21 / \mathrm{bbl})$ 


\section{Results-Jurisdiction}

- Jurisdiction over produced water in SE NM is primarily under the Oil Conservation Division;

- Reuse within the O\&G industry is streamlined now by new regulations;

- No water right is associated with produced water.

- Reuse outside of oil and gas industry likely will require either/both of NMED discharge permits and NPDES permits (EPA) 


\section{Acknowledgements and Contact Information}

- Funding provided by the New Mexico Environment Department, Drinking Water Section, and Los Alamos National Laboratory

- Reviews by the NMED, EMNRD, NM Office of the State Engineer, the NM Oil Conservation Division, and U.S. EPA Region 6.

For More Information:

- Produced Water Project Website: https://nmwrri.nmsu.edu/producedwaterl

- New Mexico WAIDS website for produced water quality data:

http:/loctane.nmt.edu/waterquality/data/nmwaidsSampleSearch.aspx

- Robert Sabie: rpsabie@nmsu.edu

- Jeri Sullivan Gmam,Ph.D, ejs@iant.gov or mienirsullukan orahanpostate.nm.us 